ISSN 2159-5542 (Print)

ISSN 2159-5550 (Online) DOI:10.17265/2159-5542

PSYCHOLOGY RESEARCH

Volume 8, Number 10, October 2018
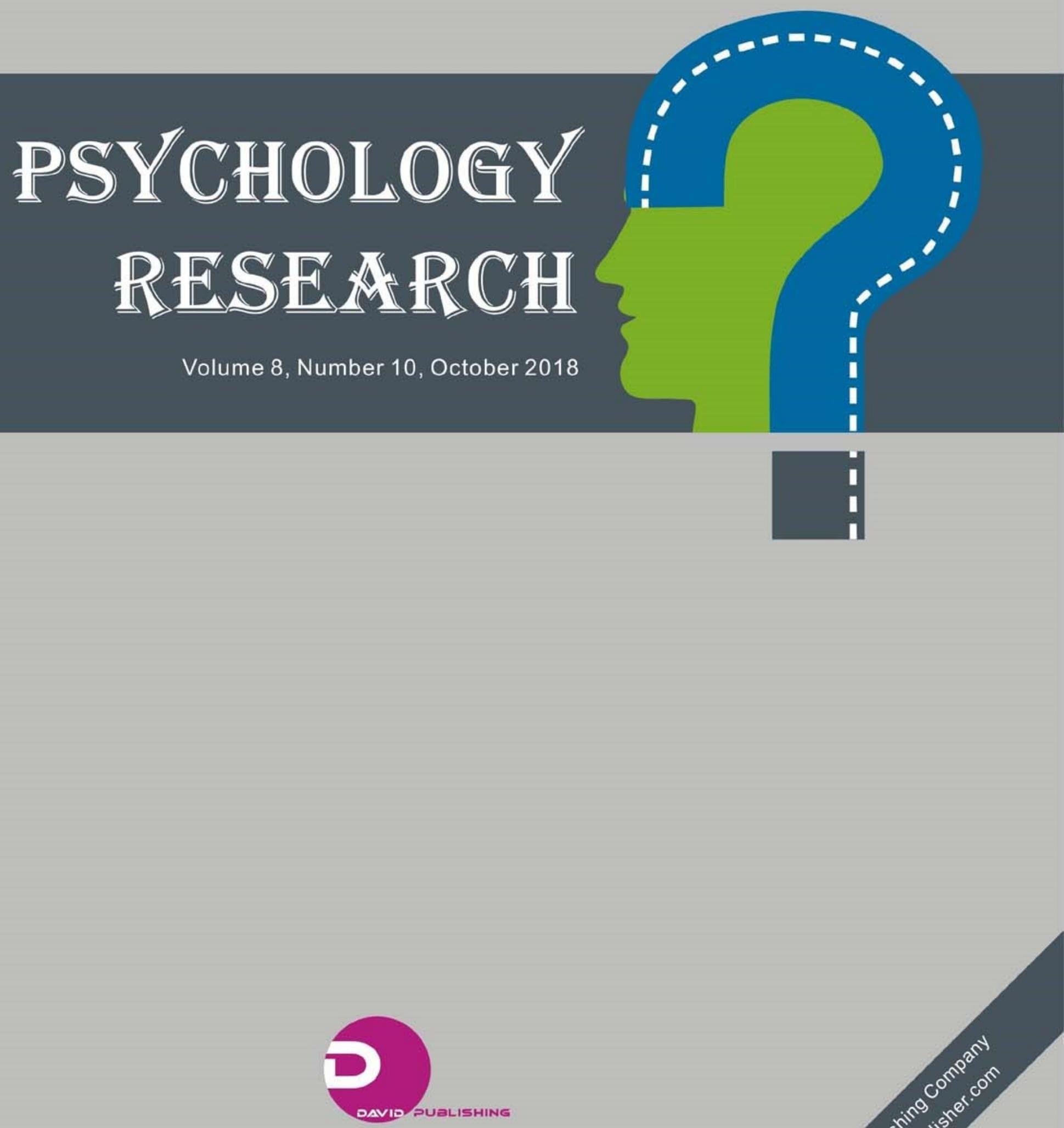


\title{
Respiratory Control Technique and Heart Rate Variability in a Child With Attention Deficit and Hyperactivity Disorder: A Case Study
}

\author{
David Catela, Susana Alves, Isabel Piscalho
}

Polytechnic Institute of Santarém, Santarém, Portugal

\begin{abstract}
Attention deficit/hyperactivity disorder (ADHD) is associated to a lower respiratory sinus arrhythmia (RSA) and to a lower heart rate variability (HRV). The purpose of this study is to verify if through breath control, an ADHD boy (9 years old) could increase HRV. During breathing control, the child significantly reduced breathing frequency (BF) and heart rate (HR); significantly augmented mean RR interval and pNN50; augmented HRVi (ns) and HF (ns); and reduced LF/HF ratio (ns). Consequently, during short training sessions, this child had the capacity to augment various parameters of HRV, suggesting an increasing of vagal activity. If vagal activity was reinforced during breathing control, it means that maybe a process of bottom-up adjustment of attention and emotional responses can be promoted.
\end{abstract}

Keywords: ADHD, breathing technique, child, HRV

\section{Introduction}

Attention deficit/hyperactivity disorder (ADHD) is described as a persistent disorder of inattention or lack of concentration and/or impulsivity/hyperactivity, which manifests itself more sharply and severely than usual in people with the same level of development, interfering in a significant way in the academic, social, or labour productivity. The inattention manifests itself mainly in rambling, lack of persistence, and difficulty in maintaining focus; the hyperactivity is attributed to excessive motor activity (American Psychiatric Association [APA], 2013; Cantwell \& Baker, 1991).

The main difficulties in this disturbance are expressed in executive functions, which are based on a set of cognitive processes that control movement, planning, organization, and inhibitory control (Barkley, 2016). Risk factors include low birth weight, smoking or alcohol consumption during gestation, child neglect or abuse, heredity (first degree), visual and auditory deficits, metabolic abnormalities, and epilepsy, among other deficiencies (Lindström, Lindblad, \& Hjern, 2011; Morales, Polizzi, Sulliotti, Mascolino, \& Perricone, 2013).

The ADHD has a prevalence rate ranging from 3\% to $7 \%$ among school-age children (Rash \& Aguirre-Camacho, 2012). However, an assertive and contextualized diagnosis is essential (Strecht, 2018), so as

David Catela, Ph.D., Applied Psychology Coordinator (UIIPS), Life Quality Research Center (CIEQV)-Polytechnic Institute of Santarém, Santarém, Portugal.

Susana Alves, Pg.Dip., Special Needs Education Specialist, Polytechnic Institute of Santarém, Santarém, Portugal.

Isabel Piscalho, M.Sc., Clinical Psychologist, Higher School of Education, Polytechnic Institute of Santarém, Santarém, Portugal. 
not to confuse with less tolerance of relatives and teachers, the restlessness, and need for movement (Salgueiro, 1987).

Currently, there is a fear of trivializing drug intervention (Strecht, 2018). In Sweden, the National Board of Health and Welfare (2002) had stated that medication should be reserved for cases where other support interventions fail, being restricted to specialists with experience in the treatment of this disorder and offering the national health system qualified free psychiatric and paediatric assistance for symptoms of ADHD (Lindström et al., 2011). In addition, it is important to note that there is a lack of knowledge about the treatment of this disorder. Necessary medication should be seen as a complement to other forms of building child' capacities and competencies, because medication alone, without psychotherapeutic and/or psychosocial intervention, does not solve the cause/origin of this disorder (Strecht, 2018). An intervention with parental training associated with training programs and behavioral interventions in the classroom is an example as the first treatment line for moderate difficulties (Young \& Amarasinghe, 2010). The development of self-regulation skills, simultaneously with parental intervention is also recommended (Marques, 2017).

Thus, complementary interventions, such as Yoga are beginning to be used (Jensen \& Kenny, 2004; Stück \& Gloeckner, 2005), mainly because their breathing techniques may have therapeutic value (Shannahoff-Khalsa \& Kennedy, 1993; Jella \& Shannahoff-Khalsa, 1993). In fact, the school-based Yoga programs for children with ADHD (Peck, Kehle, Bray, \& Theodore, 2005; Abadi, Madgaonkar, \& Venkatesan, 2008) and their families (Harrison, Manocha, \& Rubia, 2004) are spreading. In Yoga, certain breathing techniques are based on the reduction of rhythm and the lengthening of breathing cycles, in order to promote an increase in respiratory sinus arrhythmia (RSA). RSA is the heart rate variation that accompanies respiration. The heart rate increases during inspiration and decreases during expiration. Cardiac measurements have been used to provide ADHD, disruptive and non-disruptive validation (Dykman, Ackerman, \& Oglesby, 1992). RSA is higher among children with typical development than in children taking ADHD medication, but children without taking ADHD medication still have a lower RSA (Buchhorn et al., 2012). Frequently, BF occurs between nine and 24 breaths per minute. At approximately six breaths per minute, there is an increase in RSA amplitude, which is a rhythm that can be achieved with some training (Lehrer, E. Vaschillo, \& B. Vaschillo, 2000). RSA is important because it determines HRV; which is assumed to be a cardiac autonomic activation index (Lin, Tai, \& Fan, 2014), and its high frequency component (HF), from 0.15 to $0.40 \mathrm{~Hz}$, is taken as an indicator of activation of the parasympathetic nervous system (Reyes del Paso, Langewitz, Mulder, Roon, \& Duschek, 2013), which is related to psychological factors, such as attention and emotional regulation (Thayer \& Lane, 2009). This process is possible because the HR is under peripheral tonic inhibitory control through the vagus nerve (Levy, 1990; Uijtdehagge \& Thayer, 2000). Higher amplitude of RSA, higher HRV, and higher HRV levels at rest provide adequate emotional responses to the context (Ruiz-Padial, Sollers, Vila, \& Thayer, 2003; Thayer \& Brosschot, 2005). Emotional dysregulation is associated with ADHD in children and is also associated with HRV (Bunford et al., 2017). In fact, childhood ADHD is associated with abnormal parasympathetic mechanisms involved in emotional regulation (Musser et al., 2011). At the cognitive level, people with low baseline HRV present higher cortisol production in the face of cognitive challenges, compared to those with elevated HRV at rest (Johnsen, Hansen, Sollers, Murison, \& Thayer, 2002). HRV is also positively associated with situational awareness, a critical factor for the central executive system to make appropriate decisions and actions in stressful and critical situations, which in turn is positively associated with its productivity (Saus et al., 2006). However, children with ADHD have significantly higher mean HR, a 
significantly lower HRV and a significantly higher LF/HF ratio than children with typical development (Tonhajzerova et al., 2009; Carvalho et al., 2014).

Since HRV is associated with performance and stress responses (Catela et al., 2018), it was questioned whether respiratory control would be able to regulate the HRV of children with probable ADHD. Vital signs of 10 children $(11.22 \pm 0.42$ years, three girls) were collected for six minutes in supine position under two conditions: i) normal breathing; and (ii) slow abdominal breathing (AB) through the Polar V800 Cardiofréquencemètre, with HRV analysis using the gHRV software. During AB, BF significantly reduced and SD2 increased significantly; additionally, the HR decreased, the mean RR interval, the rMSSD, and the HRV index increased (ns). The authors consider that all these modifications indicate an increase in vagal activity during $\mathrm{AB}$, with these children being able to explore a respiratory control technique in a short and single session. However, they observe somewhat elevated values of the LF/HF ratio, suggesting that there is still intense sympathetic involvement during their practice (Malliani, Lombardi, \& Pagani, 1994).

As an increase in HRV is positively associated with performance and situational awareness (Saus et al., 2006), we went to verify whether the appropriation of a respiratory control technique would allow the HRV to be regulated in a child with ADHD, in order to provide him with emotional regulation and attention, in the performance of academic tasks, as well as in the ability to adapt to stressful situations. Both the sympathetic and parasympathetic systems are involved in the regulation of respiration, so it is expected that with the practice of the technique, the HF increases and the LF/HF ratio decreases. Increased numbers of HRV indicators during slow, predominantly abdominal, and controlled breathing may be indicative of vagal activity. If vagal activity is stimulated during this type of breathing (Levy, 1990, Uijtdehagge \& Thayer, 2000), this means that perhaps a bottom-up process of adjustment of attention and emotional responses can be promoted (Ruiz-Padial et al., 2003; Thayer \& Brosschot, 2005; Thayer \& Lane, 2009).

\section{Methods}

\section{Participant}

The participant of this study is a child with ADHD, male, 9 years old, elementary school student. When perturbed the child presents involuntary stereotyped movements, andshort episods of priapism. He has access to special education support, and is medicated (Risperidone $0.5 \mathrm{mg}$, every day in the morning and at night; and Rubifen $10 \mathrm{mg}$, on the school days, in the morning). The child is a dizygotic twin, was born at 27 weeks of gestation, weighing $875 \mathrm{~g}$; and resuscitation was required. The Apgar score at the first minute was five and at the fifth minute was seven. He started pre-school education at age of three, having attended kindergarten for four years. He benefited from educational measures under the Portuguese Decree-Law No. 3/2008, January 7 , the year before entering the 1st Cycle of Basic Education. Currently, he attends a class of the first degree, composed by 25 students. He presents learning difficulties with global developmental delay, hyperkinetic and impulsive behaviour, and relational immaturity. He reveals positive school results, although with slow pace work, with little autonomy in the accomplishment of the tasks, with periods of attention and concentration very short, needing a lot of individualized support. He benefits of Speech and Occupational Therapy.

\section{Procedures and Protocol}

Informed consent and assent were obtained. The procedures used are in compliance with international standards for human experimentation. Data collecting was always carried out by one of the authors of the study, 
known to the child, after the training of protocols. The vital signs were collected for six to seven minutes, in dorsal decubitus, during 13 sessions, for each of two conditions, always in the order indicated: 1) normal breathing (NB) - as baseline; and 2) slow abdominal breathing (AB) - for the training and practice of respiratory control technique, similar but considerably simpler than that proposed by Lehrer et al. (2000). The following verbatim was used: (1) put one hand on your chest and the other on your belly; (2) breathe only through your nose; and (3) fill your belly with air and then let it out slowly. The duration or rhythm of breathing cycles was not controlled, so that the child could breathe comfortably.

The temperature and humidity of the room where the data collecting took place were as follows (see Table 1):

Table 1

Descriptive Statistics $\left(M, S D\right.$, min, max) and Inferential Statistics $(Z, r, r r b)$ for Temperature $\left({ }^{\circ} C\right)$ and Humidity (perc Entage) During the 13 Sessions, for the NB (Baseline) and AB (Slow Abdominal Breathing) Conditions

\begin{tabular}{llllll}
\hline & Condition & $M \pm S D(\min , \max )$ & $\mathrm{Z}$ & $r$ & $r r b$ \\
\hline \multirow{2}{*}{ Temperature } & $\mathrm{NB}$ & $22.46 \pm 1.20(21,25.2)$ & $-2.755^{* *}$ & \multirow{2}{*}{0.76} & \multirow{2}{*}{0.83} \\
\multirow{2}{*}{ Humidity } & $\mathrm{AB}$ & $23.10 \pm 1.34(21,26,2)$ & & & \multirow{2}{*}{0.46} \\
& $\mathrm{NB}$ & $52.23 \pm 3.98(46,61)$ & $-1.471, \mathrm{~ns}$ & 0.41 & 0 \\
\hline
\end{tabular}

Notes. ${ }^{* *} p<0.01 ;{ }^{*} p<0.05 ; \mathrm{ns}$ - non-significant. M-mean, SD-standard deviation, min-minimum, max-maximum; ZWilcoxon, $\mathrm{r}$ - effect size, rrb-Wilcoxon rank-biserial correlation coefficient.

As can be observed the temperature was significantly higher during the collection in the $\mathrm{AB}$ condition, which may have affected the vital signs collected. In fact, in the $A B$ condition, the Spearman correlation revealed a significant direct association between humidity percentage and breathing frequency $[r h o(13)=$ $\left.0.649^{*}\right]$ and significant inverse association between room temperature and breathing frequency $[$ rho $(13)=$ $\left.-0.563^{*}\right]$; which was not found for the NB condition $[r h o(13)=0.481, \mathrm{~ns} ;$ rho $(13)=-0.273$, ns, respectively].

However, in the two conditions, there was no association between mean heart rate and temperature or humidity of the room.

Data collecting of HRV was performed using the Polar V800 (Giles, Draper, \& Neil, 2016). The breathing frequency was obtained through direct observation, with confirmation of counting through cycles of respiratory sinus arrhythmia in the $\mathrm{AB}$ condition.

\section{Data Treatment}

The HRV analysis was performed using the gHRV software (Rodríguez-Liñares, Méndez, Vila, \& Lado, 2012; Vila et al., 1997). After visual inspection of the time series of the RR intervals, for the detection and elimination of false beats (Peltola, 2010), the HR data were automatically filtered and interpolated according to Rodríguez-Liñares et al. (2012). Frequency analysis was obtained according to Vila et al. (1997). For the spectral analysis, the interpolation of the signal was made at $4 \mathrm{~Hz}$. The window amplitude and time displacement were $120 \mathrm{~s}$ and $60 \mathrm{~s}$, respectively. Nonlinear indices were calculated following the algorithms described in Kaplan, Furman, and Pincus (1990) and Pincus and Goldberger (1994). In the analysis of the time series, for the m-dimension and the delay procedures were taken according to Kantz and Schreiber (2004) and Cao (1997) respectively. 


\section{Statistical Analyses}

Data were statistically treated in the IBM-SPSS program, v.24, at a significance level of 0.05 . The Shapiro-Wilk test was used to verify the normality of the data distribution. Although most of the data had revealed a normal distribution, given the sample size we opted for the Wilcoxon $(Z)$ test, with Monte Carlo test (99\% confidence level, 10,000 sample tables), and estimation of effect size $r$ (Field, 2013) and the Wilcoxon rank-biserial correlation coefficient $(r r b)$ (Kerby, 2014). For the analysis of the evolution of the breathing frequency $\left(Z_{M d}\right)$ throughout the sessions, the Median value was used, with Monte Carlo test (confidence level $99 \%, 10,000$ sample tables). Also, the inverse and cubic models of curve adjustment were used, with adjusted $R^{2}$ estimate and respective ANOVA $(F)$, standardized coefficient for the number of sessions (Beta) and respective test $\mathrm{t}(t)$. The Spearman (rho) test was used for analysis of association between variables, with Bootstrap test $(95 \%$ confidence level, 1,000 samples, simple sampling, corrected confidence interval and accelerated by bias).

\section{Results}

The child significantly reduced breathing frequency in the $\mathrm{AB}$ condition. In addition, the sequence test revealed no randomness for the time series of the NB condition (see Table 2).

Table 2

Descriptive Statistics (M, SD, min, max, $M d, P)$ and Inferential Statistics $\left(Z, r, r r b, Z_{M d}\right)$ for the Respiratory Rate (Cycles per Minute) Over the 13 Sessions, Under NB (Baseline) and AB (Slow Abdominal Breathing) Conditions

\begin{tabular}{llllllllll}
\hline Condition & $M \pm S D$ (min, max $)$ & $M d$ & $P 25$ & $P 50$ & $P 75$ & $Z$ & $r$ & $r r b$ & $Z_{M d}$ \\
\hline $\mathrm{RN}$ & $15.07 \pm 2.98(11,23)$ & 14 & 13 & 14 & 17 & \multirow{2}{*}{$-7.636^{* * *}$} & \multirow{2}{*}{0.77} & 0.73 & $-4.633^{* * *}$ \\
$\mathrm{AB}$ & $12.22 \pm 1.16(10,16)$ & 12 & 11 & 12 & 13 & & & & $-2.040, \mathrm{~ns}^{\mathrm{a}}$ \\
\hline
\end{tabular}

Notes. $^{* * *} p<0.001 ; \mathrm{ns}$ - non-significant; ${ }^{\text {a }}$ after Monte Carlo correction. mean-M, standard deviation - SD, minimum - min, max - maximum, median - Md, percentiles - P; Wilcoxon $-Z$, effect size $-r$, Wilcoxon rank-biserial correlation coefficient $-\mathrm{rrb}$, sequences test $-Z_{\mathrm{Md}}$.

In both conditions, we obtained a better adjustment of the cubic and inverse curve, which were only significant for the NB condition (see Table 3).

Table 3

Adjustment of Cubic and Inverse Curve $\left(R^{2}\right)$ and Respective ANOVAs (F, Degrees of Freedom of Regression and Residual in Parentheses), and Standardized Coefficient (Beta) With Respective $t(t)$ Test for Number of Sessions, in the Respiratory Rate (Cycles per Minute) Over the 13 Sessions, in the NB (Baseline) and AB (Slow Abdominal Breathing) Conditions

\begin{tabular}{llllll}
\hline Condition & Model & $R^{2}$ & $F(3,88)$ & Beta & $t$ \\
\hline NB & Cubic & 0.521 & $33.997^{* * *}$ & -4.208 & $-4.769^{* * *}$ \\
AB & & 0.041 & $2.289, \mathrm{~ns}$ & 0.601 & $0.631, \mathrm{~ns}$ \\
Condition & Model & $\mathrm{R}^{2}$ & $\mathrm{~F}(1,90)$ & Beta & $\mathrm{t}$ \\
NB & & 0.469 & $81.371^{* * *}$ & 0.689 & $9.021^{* * *}$ \\
AB & Inverse & 0.031 & $3.923, \mathrm{~ns}$ & 0.204 & $1.981, \mathrm{~ns}$ \\
\hline
\end{tabular}

Notes. ${ }^{* * *} p<0.001 ; \mathrm{ns}$ - non-significant.

This curve tendency is quite differentiable in the graphs (see Figure 1). It should be noted that in the 13th session the observed values for respiratory rate (circles) are very similar in both conditions. 

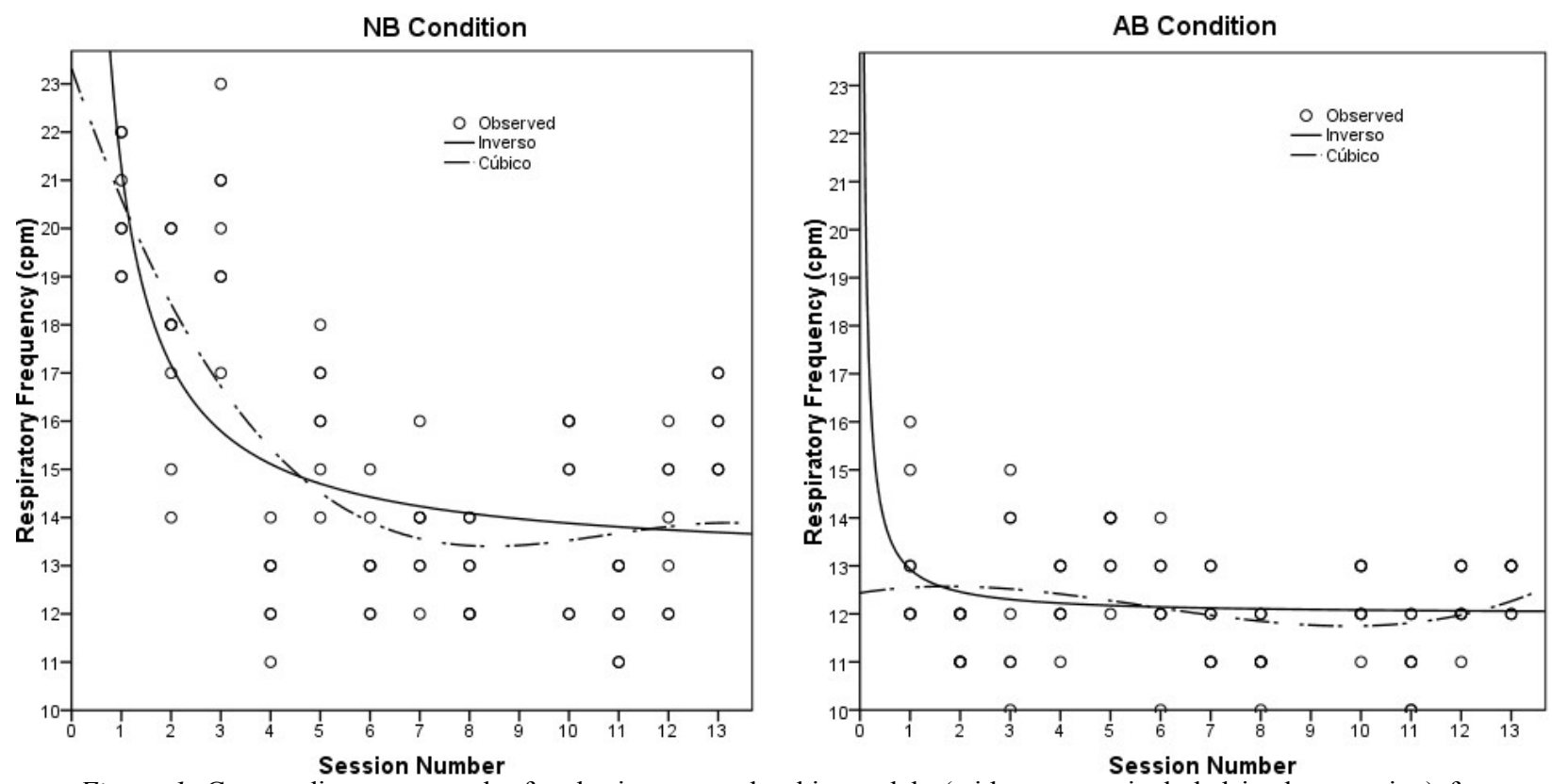

Figure 1. Curve adjustment graphs for the inverse and cubic models (with constant included in the equation) for respiratory rate evolution over the 13 sessions, in the NB condition (left) and the $\mathrm{AB}$ condition (right).

The child significantly reduced the mean heart rate (HR) in the $\mathrm{AB}$ condition compared to the NB (see Table 4 and Figure 2).

Table 4

Descriptive Statistics (M, SD, Md, P) and Inferential Statistics (Z, $r, r r b)$ for Mean Heart Rate (Beats per Minute) During the 13 Sessions, Under NB (Baseline) and AB (Slow Abdominal Breathing) Conditions

\begin{tabular}{lllllllll}
\hline Condition & $M \pm S D$ & $M d$ & $P 25$ & $P 50$ & $P 75$ & $Z$ & $r$ & $r r b$ \\
\hline $\mathrm{RN}$ & $76.06 \pm 2.63$ & 75.72 & 73.90 & 75.72 & 77.88 & \multirow{2}{*}{ (3.059** } & \multirow{2}{*}{0.85} & 1.00 \\
$\mathrm{AB}$ & $12.22 \pm 1.16$ & 68.94 & 66.69 & 68.94 & 71.87 & & & \\
\hline
\end{tabular}

Notes. ${ }^{* *} p<0.001$. mean-M, standard deviation-SD, median-Md, percentiles-P; Wilcoxon-Z, effect size - $\mathrm{r}$, Wilcoxon rank-biserial correlation coefficient- rrb.

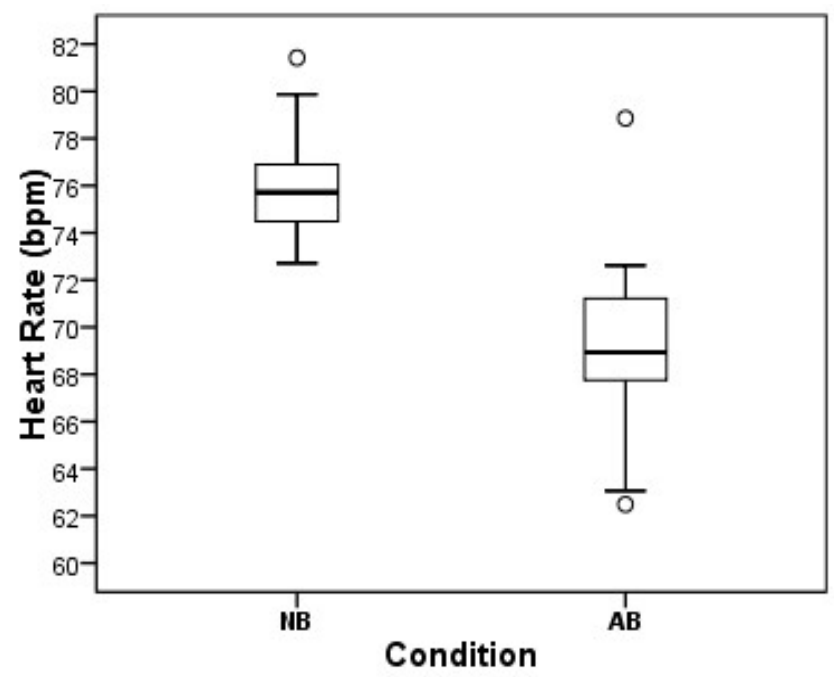

Figure 2. Boxplot for mean heart rates of the 13 sessions, in the NB (baseline) condition and the AB (slow abdominal breathing) condition. 
The main HRV indicators significantly increased and the LF/HF ratio significantly decreased, from the NB condition to the AB condition, except for SD2 and LF (see Table 5).

Table 5

Descriptive Statistics (M, SD, Md) and Inferential Statistics (Z, r, rrb) for HRV Measurements of the 13 Sessions in Baseline and AB (Slow Abdominal Breathing)

\begin{tabular}{|c|c|c|c|c|c|c|c|}
\hline Measure & Condition & $M \pm S D$ & $M d$ & $Z$ & $r$ & $r r b$ & $Z_{M d}$ \\
\hline \multirow{2}{*}{ RR Mean Interval (ms) } & NB & $812.43 \pm 26.93$ & 818.70 & \multirow{2}{*}{$-3.059^{* *}$} & \multirow{2}{*}{0.84} & \multirow{2}{*}{-1.00} & $-4.633^{* * *}$ \\
\hline & $\mathrm{AB}$ & $893.77 \pm 54.24$ & 895.31 & & & & $-2.040, \mathrm{~ns}^{\mathrm{a}}$ \\
\hline \multirow{2}{*}{ pNN50 (\%) } & NB & $62.98 \pm 4.73$ & 63.64 & \multirow{2}{*}{$-2.589^{* *}$} & \multirow{2}{*}{0.72} & \multirow{2}{*}{-0.50} & $-4.633^{* * *}$ \\
\hline & $\mathrm{AB}$ & $68.00 \pm 3.38$ & 68.48 & & & & $-2.040, \mathrm{~ns}^{\mathrm{a}}$ \\
\hline \multirow{2}{*}{ rMSSD (ms) } & NB & $134.88 \pm 16.17$ & 136.55 & \multirow{2}{*}{$-2.981^{* * * a}$} & \multirow{2}{*}{0.83} & \multirow{2}{*}{-0.83} & $-4.633^{* * *}$ \\
\hline & $\mathrm{AB}$ & $149.36 \pm 11.32$ & 149.46 & & & & $-2.040, \mathrm{~ns}^{\mathrm{a}}$ \\
\hline \multirow{2}{*}{ SD1 (ms) } & NB & $95.48 \pm 11.45$ & 96.67 & \multirow{2}{*}{$-2.981^{* * * a}$} & \multirow{2}{*}{0.83} & \multirow{2}{*}{-0.83} & $-4.633^{* * *}$ \\
\hline & $\mathrm{AB}$ & $105.72 \pm 8.02$ & 105.80 & & & & $-2.040, \mathrm{~ns}^{\mathrm{a}}$ \\
\hline \multirow{2}{*}{ SD2 (ms) } & NB & $167.33 \pm 23.01$ & 178.09 & \multirow{2}{*}{$-0.549, \mathrm{~ns}$} & \multirow{2}{*}{0.77} & \multirow{2}{*}{0.17} & $-4.633^{* * *}$ \\
\hline & $\mathrm{AB}$ & $168.63 \pm 11.56$ & 168.37 & & & & $-2.040, \mathrm{~ns}^{\mathrm{a}}$ \\
\hline \multirow{2}{*}{$\mathrm{LF}\left(\mathrm{ms}^{2}\right)$} & NB & $2839.30 \pm 896.26$ & 2889.21 & \multirow{2}{*}{$0.000, \mathrm{~ns}$} & \multirow{2}{*}{0.00} & \multirow{2}{*}{0.17} & $-4.633^{* * *}$ \\
\hline & $\mathrm{AB}$ & $2908.16 \pm 489.21$ & 2926.56 & & & & $-2.040, \mathrm{~ns}^{\mathrm{a}}$ \\
\hline \multirow{2}{*}{$\mathrm{HF}\left(\mathrm{ms}^{2}\right)$} & NB & $3168.05 \pm 1011.43$ & 3102.68 & \multirow{2}{*}{$-2.040^{*}$} & \multirow{2}{*}{0.56} & \multirow{2}{*}{-0.50} & $-4.633^{* * *}$ \\
\hline & $\mathrm{AB}$ & $3810.98 \pm 598.30$ & 3850.94 & & & & $-2.040, \mathrm{~ns}^{\mathrm{a}}$ \\
\hline \multirow{2}{*}{$\mathrm{LF} / \mathrm{HF}$} & NB & $1.04 \pm 0.32$ & 1.16 & \multirow{2}{*}{$-2.353^{*}$} & \multirow{2}{*}{0.65} & \multirow{2}{*}{-0.67} & $-4.633^{* * *}$ \\
\hline & $\mathrm{AB}$ & $0.81 \pm 0.19$ & 0.81 & & & & $-2.040, \mathrm{~ns}^{\mathrm{a}}$ \\
\hline
\end{tabular}

Notes. ${ }^{* * * *} p<0.001 ;{ }^{* *} p<0.01 ;{ }^{*} p<0.05$; ns-non-significant; ${ }^{\mathrm{a}}$ after Monte Carlo correction; mean-M, standard deviation-SD, median-Md; Wilcoxon-Z, effect size-r, Wilcoxon rank-biserial correlation coefficient—rrb.

Although the RR mean interval did not reveal significant associations in the $\mathrm{NB}$ condition, the $\mathrm{AB}$ condition revealed the same significant direct association $\left[r h o(13)=0.626^{*}\right]$ with rMSSD, SD1, and SD2. However, it was LF that in the NB condition revealed significant positive associations with rMSSD $[$ rho $(13)=$ $\left.0.698^{* *}\right]$, SD1 $\left(r h o(13)=0.698^{* *}\right), \operatorname{SD} 2\left(r h o(13)=0.835^{* *}\right)$ and pNN50 $\left[r h o(13)=0.654^{*}\right]$; only showing in the $\mathrm{AB}$ condition, a significant positive association with the $\mathrm{LF} / \mathrm{HF}$ ratio $\left[r h o(13)=0.692^{* *}\right]$. Additionally, in the $\mathrm{NB}$ condition, there is a significant inverse association between $\mathrm{HF}$ and $\mathrm{LF} / \mathrm{HF}$ ratio $\left[\right.$ rho $\left.(13)=-0.742^{* *}\right]$ and tendency for inverse association in the $\mathrm{AB}$ condition $[r h o(13)=-0.563, p=0.061]$. Finally, pNN50 which in NB condition revealed significant positive associations with $\operatorname{LF}\left[r h o(13)=0.654^{*}\right], \operatorname{rMSSD}\left[r h o(13)=0.681^{*}\right]$, $\mathrm{SD} 1\left[r h o(13)=0.681^{*}\right]$, and SD2 $\left[r h o(13)=0.665^{*}\right]$, did not reveal any significant association in the AB condition. In both conditions rMSSD showed a total association with SD1 $[r h o(13)=1]$, and a significant direct association with SD2 in the NB condition $\left[r h o(13)=0.863^{* *}\right]$ and $\mathrm{AB}$ condition $\left[r h o(13)=0.813^{* *}\right]$, as well as those already mentioned with LF and HF; and SD1 and SD2 were significantly associated in both NB [rho(13) $\left.=0.863^{*}\right]$ and $\mathrm{AB}\left[\right.$ rho $\left.(13)=0.813^{*}\right]$ conditions.

\section{Discussion}

During short sessions of respiratory control practice, this child had the capacity to significantly reduce HR and breathing frequency; and to increase several HRV parameters. All these modifications indicate an increase in vagal activity during AB. If vagal activity was reinforced during AB (Levy, 1990; Uijtdehaage \& Thayer, 2000), this means that it is probably possible to provide him with a bottom-up self-adjustment of his emotional responses and attention span (Ruiz-Padial et al., 2003; Thayer \& Brosschot, 2005; Thayer \& Lane, 2009). More 
relevant is the fact that, in parallel, it was observed that during the 13 sessions, there was a significant reduction of the breathing frequency in the BN condition.

It is noteworthy that HF as an indicator of parasympathetic activity (Camm et al., 1996; Reyes del Paso et al., 2013), increased significantly in the AB condition compared to the NB condition; a result that is reinforced by the significant reduction of the LF/HF ratio and the significant increase of SD1; however, the same did not occur with LF or SD2.

\section{Conclusion}

A child identified with ADHD and other comorbidities was able to perform a slow and predominantly abdominal breathing technique. During the execution of this respiratory technique and based on several parameters of HRV, this child showed increased parasympathetic activity and HR reduction (Tonhajzerova et al., 2009; Griffiths et al., 2017; Imeraj et al., 2011; Rukmani et al., 2016; Carvalho et al., 2014). During the sessions, the NB data reveal a significant evolution of some parameters associated to the parasympathetic activity, such as SD1, HF, and LF/HF (Camm et al., 1996, Reyes del Paso et al., 2013), probably meaning that this child strengthened the parasympathetic activity or, at least, incorporated this respiratory technique (Marques, 2017). This hypothesis is sustainable by the significant reduction of respiratory frequency throughout the sessions.

If a HRV is directly associated with the capacity for sustained attention, the results of this intervention support the hypothesis of using this respiratory technique as a complementary and non-clinical intervention for the control of the abnormal parasympathetic mechanisms and the dysregulation of the emotions that are associated with ADHD in children (Bunford et al., 2017, Musser et al., 2011, Ruiz-Padial et al., 2003, Thayer \& Brosschot, 2005, Thayer \& Lane, 2009).

\section{References}

Abadi, M. S., Madgaonkar, J., \& Venkatesan, S. (2008). Effect of yoga on children with attention deficit/hyperactivity disorder. Psychological Studies-University of Calicut, 53(2), 154.

Achenbach, T. M. (1991). Integrative guide for the 1991 CBCL/4-18, YSR, and TRF profiles. Department of Psychiatry, University of Vermont.

American Psychiatric Association. (2013). Diagnostic and statistical manual of mental disorders (DSM-5 ${ }^{\circledR}$ ). American: American Psychiatric Publication.

Barkley, R. (2016). Recent longitudinal studies of childhood attention-deficit/hyperactivity disorder: Important themes and questions for further research. Journal of Abnormal Psychology, 125(2), 248-255.

Brennan, M., Palaniswami, M., \& Kamen, P. (2002). Poincare plot interpretation using a physiological model of HRV based on a network of oscillators. American Journal of Physiology-Heart and Circulatory Physiology, 283(5), 1873-1886.

Buchhorn, R., Conzelmann, A., Willaschek, C., Störk, D., Taurines, R., \& Renner, T. J. (2012). Heart rate variability and methylphenidate in children with ADHD. ADHD Attention Deficit and Hyperactivity Disorders, 4(2), 85-91.

Bunford, N., Evans, S. W., Zoccola, P. M., Owens, J. S., Flory, K., \& Spiel, C. F. (2017). Correspondence between heart rate variability and emotion dysregulation in children, including children with ADHD. Journal of abnormal child psychology, 45(7), 1325-1337.

Camm, A. J., Malik, M., Bigger, J. T., Breithardt, G., Cerutti, S., Cohen, R. J., ... \& Lombardi, F. (1996). Heart rate variability: Standards of measurement, physiological interpretation and clinical use. Task Force of the European Society of Cardiology and the North American Society of Pacing and Electrophysiology. Circulation, 93(5), 1043-1065.

Cantwell, D. P., \& Baker, L. (1991). Association between attention deficit-hyperactivity disorder and learning disorders. Journal of learning disabilities, 24(2), 88-95.

Cao, L. (1997). Practical method for determining the minimum embedding dimension of a scalar time series. Physica D: Nonlinear Phenomena, 110(1-2), 43-50. 
Carvalho, T. D., Wajnsztejn, R., de Abreu, L. C., Vanderlei, L. C. M., Godoy, M. F., Adami, F., \& Ferreira, C. (2014). Analysis of cardiac autonomic modulation of children with attention deficit hyperactivity disorder. Neuropsychiatric disease and treatment, 10,613.

Catela, D., Piscalho, I., Ferreira, R., Victorino, A., Cerejeira, B., Marques, N., \& Dias, S. (2018). Respiratory control technique and attention deficit hyperactivity disorder in children. BMC Health Services Research, 18 (Suppl. 2), 89-90.

Dykman, R. A., Ackerman, P. T., \& Oglesby, D. M. (1992). Heart rate reactivity in attention deficit disorder subgroups. Integrative physiological and behavioral science, 27(3), 228-245.

Field, A. (2013). Discovering statistics using IBM SPSS statistics. London: Sage.

Fonseca, A. C., Simões, A., Rebelo, J. A., Ferreira, J. A., \& Cardoso, F. (1995). O inventário de comportamentos da criança para professores-Teachers Report Form (TRF) (The Inventory of Child Behaviors for Teachers-Teachers Report Form (TRF)). Revista Portuguesa de Pedagogia, 29(2), 81-102.

Giles, D., Draper, N., \& Neil, W. (2016). Validity of the Polar V800 heart rate monitor to measure RR intervals at rest. European Journal of Applied Physiology, 116(3), 563-571.

Griffiths, K. R., Quintana, D. S., Hermens, D. F., Spooner, C., Tsang, T. W., Clarke, S., \& Kohn, M. R. (2017). Sustained attention and heart rate variability in children and adolescents with ADHD. Biological psychology, 124, 11-20.

Harrison, L. J., Manocha, R., \& Rubia, K. (2004). Sahaja yoga meditation as a family treatment programme for children with attention deficit-hyperactivity disorder. Clinical Child Psychology and Psychiatry, 9(4), 479-497.

Imeraj, L., Antrop, I., Roeyers, H., Deschepper, E., Bal, S., \& Deboutte, D. (2011). Diurnal variations in arousal: A naturalistic heart rate study in children with ADHD. European child \& adolescent psychiatry, 20(8), 381-392.

Jella, S. A., \& Shannahoff-Khalsa, D. S. (1993). The effects of unilateral forced nostril breathing on cognitive performance. International Journal of Neuroscience, 73(1-2), 61-68.

Jensen, P. S., \& Kenny, D. T. (2004). The effects of yoga on the attention and behavior of boys with attention-deficit/hyperactivity disorder (ADHD). Journal of attention disorders, 7(4), 205-216.

Johnsen, B. H., Hansen, A. L., Sollers, J. J., Murison, R., \& Thayer, J. F. (2002). Heart rate variability is inversely related to cortisol reactivity during cognitive stress. Psychosomatic Medicine, 64(1), 289.

Kantz, H., \& Schreiber, T. (2004). Nonlinear time series analysis (Vol. 7). Cambridge: Cambridge University Press.

Kaplan, D. T., Furman, M. I., \& Pincus, S. M. (1990). Techniques for analyzing complexity in heart rate and beat-to-beat blood pressure signals. In Computers in Cardiology 1990 Proceedings (pp. 243-246), 23-26 September, Chicago, Illinois.

Kerby, D. S. (2014). The simple difference formula: An approach to teaching nonparametric correlation. Comprehensive Psychology, 3, 11-IT.

Lehrer, P. M., Vaschillo, E., \& Vaschillo, B. (2000). Resonant frequency biofeedback training to increase cardiac variability: Rationale and manual for training. Applied psychophysiology and biofeedback, 25(3), 177-191.

Levy, M. N. (1990). Autonomic interactions in cardiac control. Annals of the New York Academy of Sciences, 601(1), $209-221$.

Lin, I. M., Tai, L. Y., \& Fan, S. Y. (2014). Breathing at a rate of 5.5 breaths per minute with equal inhalation-to-exhalation ratio increases heart rate variability. International Journal of Psychophysiology, 91(3), 206-211.

Lindström, K., Lindblad, F., \& Hjern, A. (2011). Preterm birth and attention deficit/hyperactivity disorder in schoolchildren. Pediatrics, 127(5), 858-865.

Malliani, A., Lombardi, F., \& Pagani, M. (1994). Power spectrum analysis of heart rate variability: A tool to explore neural regulatory mechanisms. British Heart Journal, 71(1), 1.

Marques, I. (2017). Prematuridade e ADHD o que nos diz a investigação (Prematurity and ADHD what the research tells us). Revista de Psicologia da Criança e do Adolescente, 8, 119-137.

Matza, L. S., Paramore, C., \& Prasad, M. (2005). A review of the economic burden of ADHD. Cost Effectiveness and Resource Allocation, 3(1), 5.

Morales, M. R., Polizzi, C., Sulliotti, G., Mascolino, C., \& Perricone, G. (2013). Early precursors of low attention and hyperactivity in moderately and very preterm children at preschool age. Pediatric reports, 5(4), 76-80.

Musser, E. D., Backs, R. W., Schmitt, C. F., Ablow, J. C., Measelle, J. R., \& Nigg, J. T. (2011). Emotion regulation via the autonomic nervous system in children with attention-deficit/hyperactivity disorder (ADHD). Journal of abnormal child psychology, 39(6), 841-852.

Nascimento, D., Carvalho, K. \& Iwabe, C. (2012). Perfil cognitivo e motor de crianças nascidas prematuras em idade escolar: Revisão de literatura(Cognitive and motor profile of premature infants born at school age: Literature review). Rev Neurocienc, 20, 618-624. 
National Board of Health and Welfare. (2002). EpC Report. Fakta om mammor, förlossningar och nyfödda barn-Medicinska födelseregistret 1973 till 2000 (Facts concerning mothers, pregnancies, and newborn children—Swedish Medical Birth Registry-1973 to 2000). Stockholm, Sweden.

Peck, H. L., Kehle, T. J., Bray, M. A., \& Theodore, L. A. (2005). Yoga as an intervention for children with attention problems. School Psychology Review, 34(3), 415.

Peltola, M. (2010). Analysis of heart rate variability from 24-hour ambulatory electrocardiographic recordings. Acta Universitatis Ouluensis D Medica, 1087. Retrieved from http://jultika.oulu.fi/files/isbn9789514293498.pdf

Pincus, S. M., \& Goldberger, A. L. (1994). Physiological time-series analysis: What does regularity quantify? American Journal of Physiology-Heart and Circulatory Physiology, 266(4), 1643-1656.

Rash, J. A., \& Aguirre-Camacho, A. (2012). Attention-deficit hyperactivity disorder and cardiac vagal control: A systematic review. ADHD Attention Deficit and Hyperactivity Disorders, 4(4), 167-177.

Reyes del Paso, G. A., Langewitz, W., Mulder, L. J., Roon, A., \& Duschek, S. (2013). The utility of low frequency heart rate variability as an index of sympathetic cardiac tone: A review with emphasis on a reanalysis of previous studies. Psychophysiology, 50(5), 477-487.

Rodríguez-Liñares, L., Lado, M. J., Vila, X. A., Méndez, A. J., \& Cuesta, P. (2014). gHRV: Heart rate variability analysis made easy. Computer Methods and Programs in Biomedicine, 116(1), 26-38.

Rodríguez-Liñares, L., Méndez, A. J., Vila, X. A., \& Lado, M. J. (2012). gHRV: A user friendly application for HRV analysis. In 7th Iberian Conference on Information Systems and Technologies (CISTI 2012), 20-23 June, Madrid, Spain.

Rowland, A. S., Lesesne, C. A., \& Abramowitz, A. J. (2002). The epidemiology of attention-deficit/hyperactivity disorder (ADHD): a public health view. Developmental Disabilities Research Reviews, 8(3), 162-170.

Ruiz-Padial, E., Sollers, J. J., Vila, J., \& Thayer, J. F. (2003). The rhythm of the heart in the blink of an eye: Emotion-modulated startle magnitude covaries with heart rate variability. Psychophysiology, 40(2), 306-313.

Rukmani, M. R., Seshadri, S. P., Thennarasu, K., Raju, T. R., \& Sathyaprabha, T. N. (2016). Heart rate variability in children with attention-deficit/hyperactivity disorder: A pilot study. Annals of neurosciences, 23(2), 81-88.

Salgueiro, E. (1987). A «Instabilidade» do João (John’s “Instability”). Análise Psicológica, 4, 657-666.

Saus, E. R., Johnsen, B. H., Eid, J., Riisem, P. K., Andersen, R., \& Thayer, J. F. (2006). The Effect of brief situational awareness training in a police shooting simulator: An experimental study. Military Psychology, 18(S), 3.

Shannahoff-Khalsa, D. S., \& Kennedy, B. (1993). The effects of unilateral forced nostril breathing on the heart. International Journal of Neuroscience, 73(1-2), 47-60.

Strecht, P. (2018). Hiperatividade e défice de atenção (Hyperactivity and attention deficit). Lisboa: Fundação Francisco Manuel dos Santos.

Stück, M., \& Gloeckner, N. (2005). Yoga for children in the mirror of the science: Working spectrum and practice fields of the training of relaxation with elements of yoga for children. Early child development and care, 175(4), 371-377.

Thayer, J. F., \& Brosschot, J. F. (2005). Psychosomatics and psychopathology: looking up and down from the brain. Psychoneuroendocrinology, 30(10), 1050-1058.

Thayer, J. F., \& Lane, R. D. (2009). Claude Bernard and the heart-brain connection: Further elaboration of a model of neurovisceral integration. Neuroscience \& Biobehavioral Reviews, 33(2), 81-88.

Tonhajzerova, I., Ondrejka, I., Adamik, P., Hruby, R., Javorka, M., Trunkvalterova, Z., \& Javorka, K. (2009). Changes in the cardiac autonomic regulation in children with attention deficit hyperactivity disorder (ADHD). Indian Journal of Medical Research, 130, 44-50.

Uijtdehaage, S. H., \& Thayer, J. F. (2000). Accentuated antagonism in the control of human heart rate. Clinical Autonomic Research, 10(3), 107-110.

Vila, J., Palacios, F., Presedo, J., Fernández-Delgado, M., Felix, P., \& Barro, S. (1997). Time-frequency analysis of heart-rate variability. IEEE Engineering in Medicine and Biology Magazine, 16(5), 119-126.

Young, S. \& Amarasinghe, M. (2010). Practitioner review: Non-pharmacological treatments for ADHD-A lifespan approach. Journal of Child Psychology and Psychiatry, 51(2), 116-133. 